\title{
TH17 AND TREGULATORY CELLS IN TYPE2 DIABETIC NEPHROPATHY
} By

\section{MALAK NABIL AMIN ${ }^{1}$, ASHRAF MAHMOUD OKBA ${ }^{2}$, ABEER ABDEL HAMID EISSA $^{2}$, MOHAMED ASHARF IBRAHIM ${ }^{2}$, MONA KAMEL ZOHEIRY ${ }^{3}$ AND HODA MOHAMED ALY ABU TALEB ${ }^{4}$}

Departments of Hepatogastroenterology and Nephrology ${ }^{1}$, Clinical Immunology and Internal Medicine ${ }^{2}$, Faculty of Medicine, Ain Shams University, Cairo $11566^{1.2}$ and Departments of Immunology ${ }^{3}$ and Biostatistics and Demography, Medical Statistician $^{4}$, Environment Research, Theodor Bilharz Research Institute, Imbaba P.O. Box 30, Giza, Egypt (*Correspondence: hadhood73@yahoo.com)

\begin{abstract}
Type 2 diabetes mellitus and diabetic nephrophathy considered to be an inflammatory process in which immune cells involved in its development and progression apart from traditional metabolic and hemodynamic risk factors.

This study was designed to determine the balance between $\mathrm{T}$ helper 17 and regulatory $\mathrm{T}$ cells in Type 2 diabetic patients having diabetic nephropathy in relation to type 2 diabetic patients without renal involvement and healthy individuals.

This study included 3 groups; diabetic 2 nephrophathy patients (on basis of proteinuria and reduced GFR), diabetic patients (ADA, 2015) and healthy controls of the same age and sex Detection of T regs and Th 17 cell were evaluated; T regs expressing CD4 \& CD 25 while Th 17 cells expressing CD4 and CD161 was done by standard 2-color flow cytometry and Th17/Treg cells ratio was calculated.

The results revealed that there was higher mean Th17 and Th17/Treg cells ratio among type 2 diabetic nephropathy patients compared to other two groups. There was lower mean Treg cells among type 2 diabetic nephropathy patients compared to other two groups with very high statistically significant differences. Also, there was higher mean Th17 and Th17/Treg cells ratio among type 2 diabetic patients compared to healthy individuals with very statistically significant differences that there was a strong positive correlation between BUN, serum creatinine, proteinuria and the grade of nephrropathic affection by the ultrasound from one side and Th17 and Th17/T reg cells ratio on the other side. But this correlation was strongly negative with $\mathrm{T}$ reg cells.
\end{abstract}

Key words: Patients, Diabetes mellitus, Diabetic nephrophathy, Th17 and T reg cells levels

\section{Introduction}

Diabetic nephropathy (DN) is defined as the appearance of persistent clinical albuminuria (Albumin Excretion Rate (AER) >300 $\mathrm{mg} / 24$ hours) in an individual with diabetes for more than 5 years and concomitant retinopathy, in the absence of urinary tract infection (UTI), other renal diseases and heart failure. This process is often associated with increasing blood pressure (Stephen and Gian, 2006). It occurs in $\sim 30 \%$ of people with type 1 diabetes and $25-40 \%$ of people with type II diabetes (Phillip et al, 2006). Because of the elastic properties of the glomeruli, changes in glomerular capillary pressure are paralleled by changes in overall glomerular volume (Bernadette et al, 2007). Type 2 diabetes is not an immune disease but at this time we could consider that there is evidence that the combine of immunologic and inflammatory mechanisms play a pivotal role in its presentation, development and finally its progression (Duran-Salgado and Rubio-Guerr, 2014). An appropriate balance between pro-inflammatory (Th17 \& Th1) and anti-inflammatory (Tregs \& Th2) subsets of T cells is critical to maintain homeostasis and avoid inflammatory disease (Bogdan et al, 2011). However, $\mathrm{T}$ cell in type $2 \mathrm{DM}$ patients has been revealed to be skewed toward a pro-inflammatory phenotype requiring monocytes for maintenance and promoting chronic inflammation via elevated cytokine (Wu et al., 2011), especially IL-17 (Yousef-idaredor et al, 2014). T reg cells may participate in dampening the inflammation in the diabetic kidney (Lim and Tesch, 2012). They play a principal role 
in immune reactions including autoimmunity, transplantation tolerance, anti-infectious immunity and cancer. The cells represent about $<5 \%$ of the peripheral CD4+ $\mathrm{T}$ cell population and play a crucial role in maintenance of immune homeostasis against selfantigens (Lastovicka, 2013).

Numerical or functional deficit of $\mathrm{T}$ regs is linked to many autoimmune diseases such as rheumatoid arthritis, multiple sclerosis or type 1 diabetes. $\mathrm{T}$ reg features result from their potent capacity to reduce the activation and expansion of conventional $\mathrm{T}$ cells by suppressing biological activities like proliferation and blocking production of pro-inflammatory cytokines TNF alpha \& IFN gamma among others (Schmetterer et al., 2012).

This work aimed to study determine the balance between $\mathrm{T}$ helper 17 and regulatory T cells in type 2 DM patients with and without nephropathy, in relation to healthy controls, knowing the balance may encourage new therapeutic strategies in the treatment of type $2 \mathrm{DN}$.

\section{Patients, Materials and methods}

Sixty subjects selected from Nephrology department of Theodor Bilharz Research Institute (TBRI) and categorized into 3 groups as follow: GA (Diabetic nephropathy group): 30 type 2 diabetic patients with nephropathy as evidenced by presence of microalbuminuria (30-300 mg/d) or macroalbuminuria (more than $300 \mathrm{mg} / \mathrm{d}$ ) and/or decreased GFR (K/DOQI, 2012). GB (Diabetic group): 30 type 2 diabetic patients without nephropathy as evidenced by absence of microalbuminuria or decreased GFR. GC: 20 healthy controls volunteered from medical and paramedical staff of the same age and sex. All patients in GA \& GB were diagnosed diabetics patients (ADA, 2015).

Ethics Committee Approval: Ethics committee approval was received for this study from the ethics committee of TBRI. All individuals gave written informed consent according to ethical guidelines of the 1975 Declaration of Helsinki.

All patients and controls were subjected to detailed history, complete clinical examination, complete laboratory investigation including: blood sugar estimation including fasting blood sugar (FBS), 2h postprandial (2hPP) blood glucose level and glycated hemoglobin (standard kits), serum creatinine, blood urea and liver function tests (Kone lab autoanalyser system (Johuson et al, 2001), complete urine analysis, $24 \mathrm{hr}$ for protein estimation using quantitative photometric test, creatinine clearance estimation using pyrogallo/red (Yohnson et al, 2001), complete blood picture using automated hematology analyser Cetlac-MEK 8118 (Nihon Kohdeu), -abdominal and pelvic ultrasonography, echocardiography,

Detection of Treg cells and Th 17 cells by Flow cytometry: $2 \mathrm{ml}$ of venous peripheral blood samples were collected on EDTA tube $(1.2 \mathrm{mg} / \mathrm{mL})$ for analysis of flow cytometry. Evaluation of $\mathrm{T}$ regs \& Th 17 cell; $\mathrm{T}$ regs expressing CD4 and CD 25 while Th 17 cells expressing CD4 and CD161 was done by standard 2-color flow cytometry was performed based on Ryba and Myśliwska, 2010 for Tregs and on Chalan et al., 2013 for Th 17 cells. Using the following monoclonal antibodies: Phycoerythrin (PE)-labeled antiCD161, Phycoerythrin-Cyanine 5 (PC5)-labeled anti-CD4, Fluorescein isothiocyanate (FITC)-labeled anti-CD25 and isotypic control antibodies (Immunotech, Beckman Coulter Co., France).

Samples were analyzes using flow cytometer (Beckman Coulter Inc., Fullerton, Califorinia, USA).Calculation of the ratio

Statistical analysis was done on a computer using IBM SPSS Statistics version 24 (IBM Corp., Armonk, NY, USA) and MedCalc version 13 (MedCalc ${ }^{\circledR}$ Software bv ba, Ostend, Belgium).

Numerical variables were presented as mean and standard deviation and differences among the three study groups were compared using one-way analysis of variance (ANOVA) with application of the Dunken test for post hoc pair wise comparison whenever the ANOVA revealed a statistically 
significant difference among the groups.

Relation between binary variables and numerical variables was examined using the Man Whitney test.

\section{Results}

This study was carried out on 60 type 2 diabetic patients (30 with nephropathy \& 30 without) and 20 totally healthy individuals as a control. Those patients were carefully selected from the Nephrology Department, Theodor Bilharz Research Institute.

Table 1: Demographic data of three studied groups.

\begin{tabular}{|c|c|c|c|c|}
\hline Variable & Control (n) \% & T2DM $(n=30) \%$ & T2DM-N $(n=30) \%$ & $p$-value \\
\hline Female & (7) 35.0 & (19) 63.3 & (15) 50.0 & \\
\hline Male & (13) 65.0 & (11) 36.7 & (15) 50.0 & 0.143 \\
\hline Age $(\mathrm{yr})$ Mean \pm SD & $55.6 \pm 2.2$ & $55.6 \pm 3.1$ & $58.9 \pm 3.3^{* * *, a}$ & $<0.001$ \\
\hline
\end{tabular}

${ }^{* * *} \mathrm{p}<0.001$ significant more than control, ${ }^{\mathrm{a}} \mathrm{p}<0.001$ significant, more than T2DM= Type 2 diabetes T2DM-N $=$ Type 2 with nephropathy

Table 2: Comparison of two diabetic groups associated with hypertension and ischemic heart (Chi square test)

\begin{tabular}{|c|c|c|c|}
\hline Variable & T2DM (n) $\%$ & T2DM-N (n) $\%$ & p-value \\
\hline Hypertension & (14) 46.7 & $(24) 80.0$ & $<0.01$ \\
\hline Ischemic heart disease & (2) 6.7 & (12) 40.0 & $<0.001$ \\
\hline
\end{tabular}

Table 3: Comparison of two diabetic groups according to duration of diabetes and duration of hypertension.

\begin{tabular}{|c|c|c|c|}
\hline Group & $\begin{array}{c}\text { T2DM } \\
\mathrm{M} \pm \mathrm{SD}\end{array}$ & $\begin{array}{c}\text { T2DM-N } \\
\mathrm{M} \pm \mathrm{SD}\end{array}$ & $\mathrm{p}$-value \\
\hline Duration of DM (yr) & $3.4 \pm 1.6$ & $10.2 \pm 3.6^{* * * *}$ & $<0.001$ \\
\hline Duration of hypertension (yr) & $4.1 \pm 3.1$ & $8.4 \pm 4.7^{* * * *}$ & $<0.001$ \\
\hline \multicolumn{2}{|c}{$* *$ significant more than T2DM }
\end{tabular}

Table 4: Th 17, T reg and Th 17/T reg ratio in studied groups.

\begin{tabular}{|l|l|l|l|l|}
\hline \multicolumn{1}{|c|}{ Groups } & $\begin{array}{l}\text { Control } \\
\mathrm{M} \pm \mathrm{SD}\end{array}$ & $\begin{array}{l}\text { T2DM } \\
\mathrm{M} \pm \mathrm{SD}\end{array}$ & $\begin{array}{l}\text { T2DM-N } \\
\mathrm{M} \pm \mathrm{SD}\end{array}$ & $\mathrm{p}$-value \\
\hline Variable & $3.07 \pm 0.28$ & $5.90 \pm 0.39^{* * *}$ & $7.29 \pm 0.55^{\text {***,a }}$ & $<0.001$ \\
\hline Treg $(\%)$ & $0.34 \pm 0.05$ & $0.34 \pm 0.05$ & $0.17 \pm 0.03^{\mathrm{b}, \#}$ & $<0.001$ \\
\hline Th17/Treg ratio & $9.33 \pm 1.84$ & $18.15 \pm 3.52^{* * *}$ & $44.10 \pm 7.01^{* * *}, \mathrm{a}$ & $<0.001$ \\
\hline
\end{tabular}

less than control; ${ }^{*} \mathrm{p}<0.001$ significant less than T2DM regulatory $\mathrm{T}$ cells $=($ Tregs $), \mathrm{T}$ helper $17=(\mathrm{TH} 17)$

Three groups were comparable as regards sexes showed a higher mean age among type 2 DN compared to others $(p<0.001)$. A higher incidence of HTN and higher duration of HTN and incidence of ischemic heart disease among type $2 \mathrm{DN}$ patients compared to type 2 diabetic patients without nephropathy $(p<0.001)$. DN patients have higher albuminuria than those without nephropathy $(p<0.001)$. There were higher mean Th17 \& Th17/reg ratio and lower mean $\mathrm{T}$ reg among type $2 \mathrm{DN}$ patients compared to other groups $(p<0.001)$ and among type 2 diabetic patients compared to controls $(p<0.001)$. Type 2 diabetics and controls were comparable as regards mean $T$ regs (Figs. $4,5 \&$
6). There was strong +ve correlation between BUN, serum creatinine and proteinuria and Th17, Th17/T reg level in diabetics. There was strong negative correlation with $\mathrm{T}$ regs. The reverse occurred with creatinine clearance, there was strong negative correlation with Th17 and Th17/Treg and strong positive correlation with $\mathrm{T}$ regs.

There was significant strong positive correlation between the grades of nephropathy by ultrasound and Th17 and Th17/Treg cells ratio-level in the three groups (Fig. $13 \&$ 15). Also, there was statistically significant strong negative correlation between the grades of nephropathy by ultrasound and Treg cells level (Fig. 14).

Table 5: Receiver-operating characteristic (ROC) curve analysis for value of Th17; Treg \& Th17/Treg ratio in classification of diabetic patients to those with or without nephropathy.

\begin{tabular}{|c|c|c|c|c|c|c|}
\hline Model & AUC & Sensitivity & Specificity & PPV & NPV & CI 95\% \\
\hline Th17 & 1.00 & 100 & 100 & 100 & 100 & $88.4-100$ \\
\hline Treg & 1.00 & 100 & 100 & 100 & 100 & $88.4-100$ \\
\hline Th17/Treg ratio & 1.00 & 100 & 100 & 100 & 100 & $88.4-100$ \\
\hline
\end{tabular}




\section{Explanation of figures}

Fig. 1: Mean Th17 in the three study groups.

Fig. 2: Mean Treg in the three study groups. Error bars represent 95\% CI.Error bars represent 95\% CI.

Fig. 3: Mean Th17/Treg ratio in three study groups. Error bars represent $95 \%$ CI.

Fig. 4: Positive correlation between Th17\& creatinine $(\mathrm{r}=0.720, p<0.001)$.

Fig. 5: Negative correlation between Th17creatinine clearance in diabetics $(r=-0.796 p<0.001)$

Fig. 6: Positive correlation between Treg \& serum creatinine $(r=-0.765, p<0.001)$.

Fig. 7: Negative correlation between Th17 \& proteinuria $(\mathrm{r}=0.678, p<0.001)$.

Fig. 8: Positive correlation between Treg \& proteinuria in diabetics $(\mathrm{r}=-0.740, p<0.001)$.

Fig. 9: Negative correlation between Treg \&creatinine clearance $(\mathrm{r}=0.858, p<0.001)$

Fig. 10: Positive correlation between Th17/Treg ratio \& serum creatinine $0.755, p<0.001)$

Fig. 11: Negative correlation between Th17/Tre ratio \&creatinine clearance $(\mathrm{r}=-(\mathrm{r}=0.879, p<0.001)$.

Fig, 12: Positive correlation between Th17/Treg ratio\& proteinuria in diabetics $(r=0.739, p<0.001)$.

Fig. 13: Positive correlation between Th17 of nephropathy by US in the whole study population.

Fig. 14: Negative correlation between Treg \&grade \&grade of nephropathy by US in the whole study population.

Fig. 15: Negative correlation between the Th17/Treg ratio grade of nephropathy by US in the whole study population.

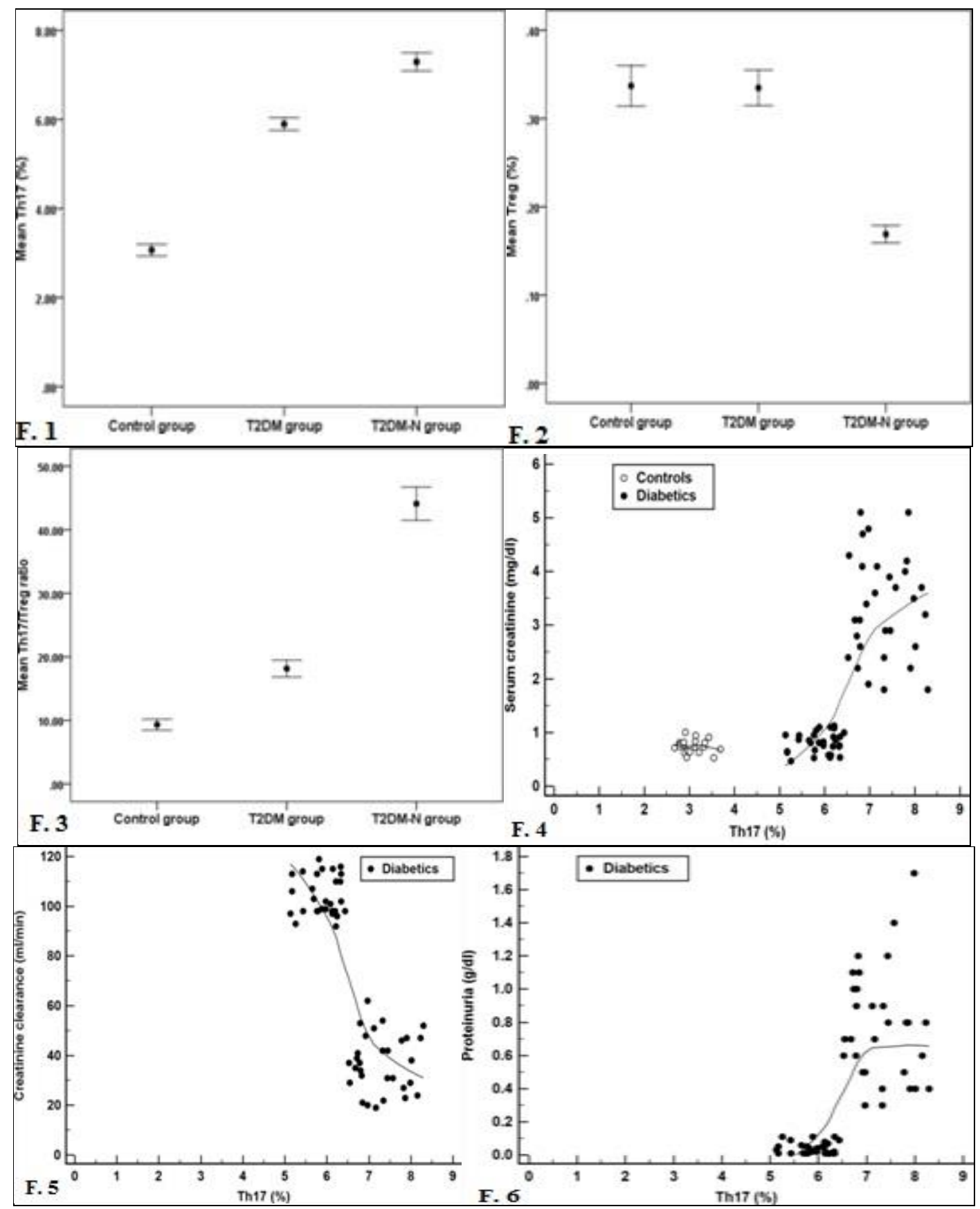



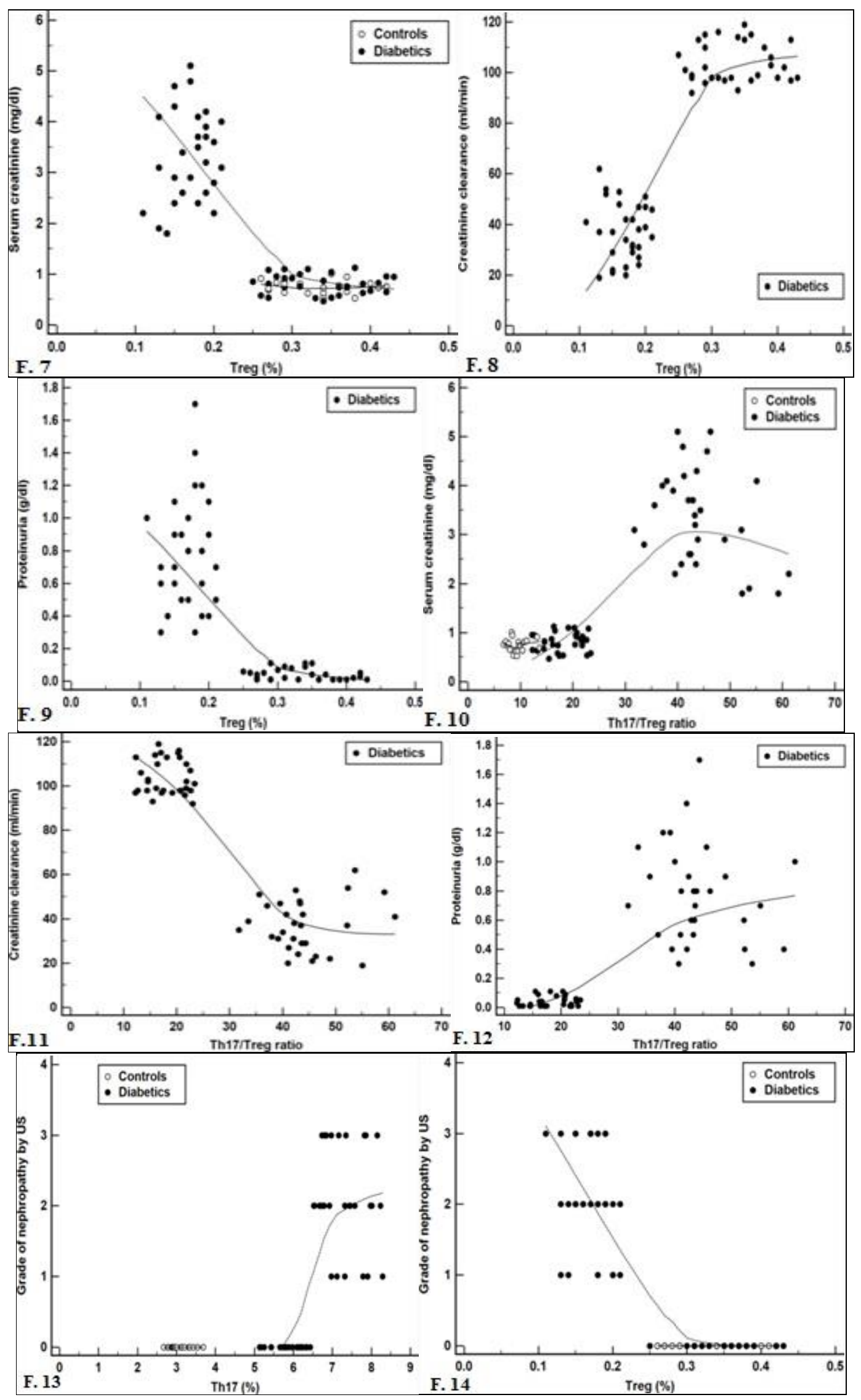

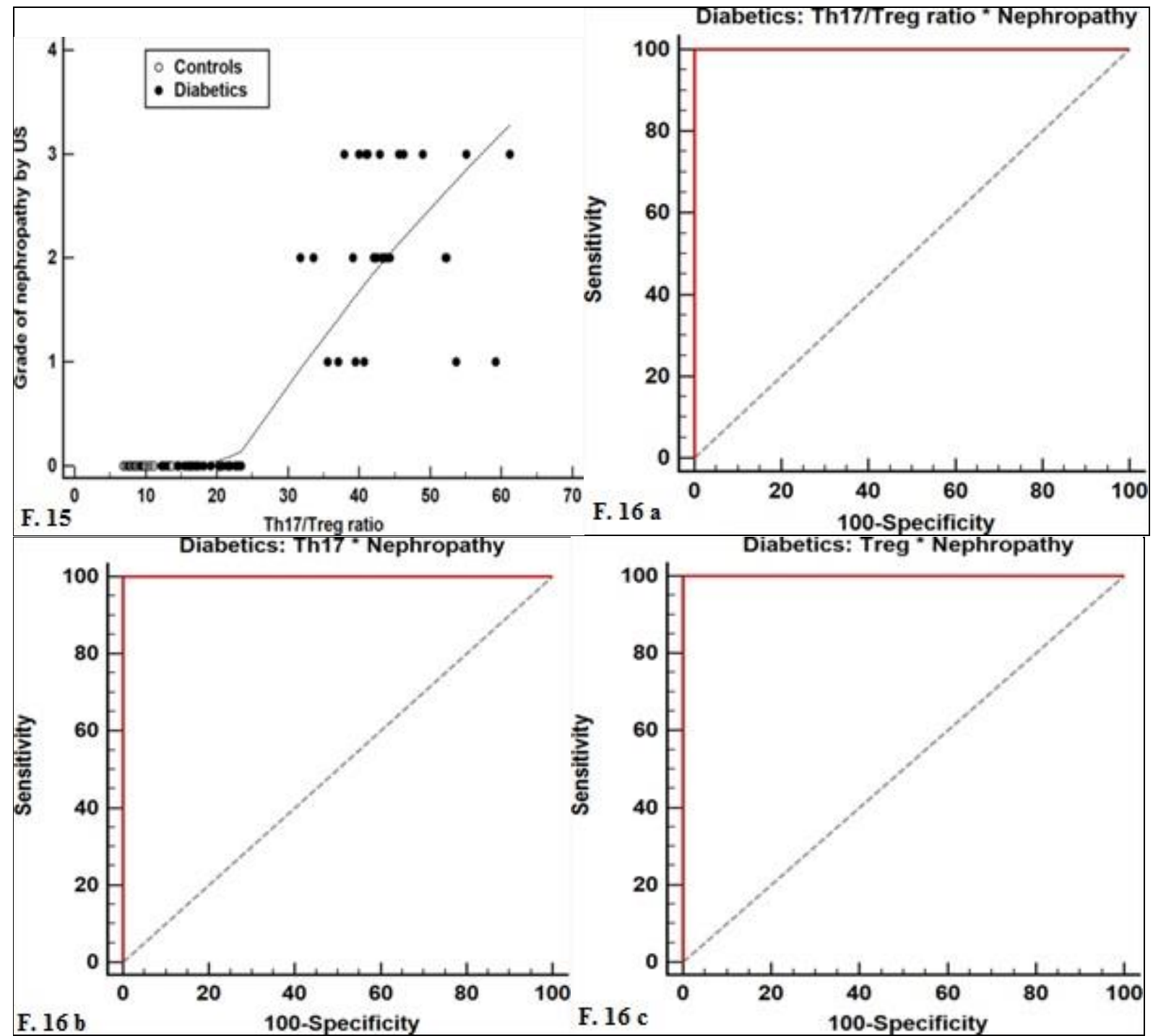

F. $16 \mathrm{~b}$ 100-Specificity

F. $16 \mathrm{c}$

Fig. 16 (a-b-c): Receiver-operating characteristic curve for value of Th17; Treg \& Th17/Treg ratio in classification of diabetic patients into those with or without nephropathy.

\section{Discussion}

T2DM is the chronic progressive metabolic disease defined by hyperglycemia (ElTawdy et al, 2016). These metabolic dysfunctions are pathologically associated with specific micro-vascular diseases and various characteristic long-term complications, including diabetic neuropathy, nephropathy and retinopathy (Wu et al, 2011). DuranSalgado and Rubio-Guerr (2014) reported that Diabetic nephropathy (DN) is the leading cause of end-stage renal failure worldwide. Besides, diabetic nephropathy is associated with cardiovascular disease, and increases mortality of diabetic patients. Several factors are involved in the pathophysiology of DN, including metabolic and hemody- namic alterations, oxidative stress, and activation of the renin-angiotensin system.

Th 17 cells produce Il 17 which is a potential inflammatory cytokine which contributes to several autoimmune and inflammatory diseases including T2DM. Recent studies sho-wed that Il 17 proved to be a potent inducer of T2DM (Yousef-idaredor et al, 2014), while $\mathrm{T}$ reg cells might participate in dampening the inflammation in the diabetic kidney; given the worsening of renal injury (Lim and Tesch, 2012).

An appropriate balance between pro-inflammatory (Th17 \& Th1) and anti-inflammatory (Tregs and Th2) subsets of T cells is critical to maintain homeostasis and avoid inflammatory disease (Bogdan et al, 2011). 
This study determined the balance between $\mathrm{T}$ helper 17 and regulatory $\mathrm{T}$ cells in type 2 diabetic patients with diabetic nephronpathy in comparison to type 2 diabetic patients without renal involvement and healthy individuals. To the best of the authors' knowledge, this is the first study performed to determine $\mathrm{T}$ helper 17 and regulatory $\mathrm{T}$ cells in type 2 diabetic patients in Egypt and also among few studies all over the world.

The statistically significant higher incidence of HTN and mean duration of HTN among type $2 \mathrm{DN}$ patients $(80 \%)$ compared to type $2 \mathrm{DM}$ patients $(46.7 \%)(p<0.001)$, which agreed with Elwakf et al. (2011) who found that $71 \%$ vs. $32 \%$ was with $p<0.05$.

Statistical significant showed higher incidence of ischemic heart disease among type 2 DN (40\%) compared to type 2 diabetic patients (6.7\%). Elwakf et al. (2011) showed the same results without statistically significant difference. Naturally, albuminuria was present in DN patients agreed with Viswanathan et al. (2012).

In the present study, there was a focus on some conditions which are usually prevalent in type 2 diabetic patients either with or without nephropathy such as hypertension and ischemic heart disease as well as relation between duration of diabetes and nephropathy.

The study showed higher mean Th17 \& Th17/Treg ratio together with lower mean $\mathrm{T}$ reg $(p<0.001)$ among type 2 DN group compared to other groups. Also, higher mean Th17 and Th17/Treg cells among type $2 \mathrm{DM}$ patients compared to controls $(\mathrm{P}<0.001)$. But, type 2 diabetes and controls were comparable as regards $\mathrm{T}$ regs without significant difference. Bogdan et al. (2011) found the same results $\mathrm{T}$ regs were decreased in diabetic patients in relation to controls, which disagreed with the present study. Zhang et al. (2014) detected surface markers of different subsets of $\mathrm{T}$ cells using ration was markedly decreased resulting in elevated Th17/Treg ratio with statistical significance $(p<0.001)$.
Statistical significant showed strong +ve correlation between proteinuria, BUN and serum creatinine and Th17 and Th17 reg in diabetics and strong -ve correlation with $\mathrm{T}$ reg cells. This agreed with those of Zhang et al. (2014) who reported that the creatinine clearance gave a reverse correlation to proteinuria, BUN and serum creatinine.

This may be the first study to consider the relation between grade of nephropathy affection by ultrasound and Th17 and Th17reg cells. It showed a strong positive correlation between the 2 arms and strong negative correlation with $\mathrm{T}$ regs.

In the present study, the ROC curve analysis revealed a cutoff value of the Th17, T reg and Th 17 at $6.43 \%, 0.21 \%$ and $23.4 \%$ respectively, could differentiate between the nephropathic diabetic patients with the sensitivity and the specificity of $100 \%$ each (area under the curve, 1 ; $95 \%$ confidence interval 0.94-1.00). In other words, measuring of the Th17 \& T reg cells in the type 2 diabetic patients was the screening test to detect renal involvement in those patients. Th17 and $T$ regs increase with incidences of deterioration of DN clinically (association with IHD and HTN) and biochemically (tests of renal function) and $\mathrm{T}$ regs the reverse effect and this can be detected even before occurrence of proteinuria or reduced GFR.

A better understanding of the mechanisms regulating the several and contradictory effects of inflammation on pancreatic islets and the kidney would help in development of effective therapies for their protection in type 2 diabetes.

\section{Conclusion}

Measuring Th17 and T reg cells levels in type 2 diabetic patients can be used as an excellent screening test to detect renal involvement in those patients; so increased Th17 cells or suppressed $\mathrm{T}$ reg cells level in patients with type 2 diabetic patients indicates renal involvement even before occurrence of proteinuria or reduced GFR with a sensitivity and specificity of $100 \%$.

\section{References}

Alizadeh, D, Katsanis, E, Larmonier, N, 2013: The multifaceted role of Th17 lymphocytes and 
their associated cytokines in cancer. Clin. Develop. Immunol. Article ID 957878, 11 pages http://dx.doi. org/ 101155/2013/957878

ADA, 2015: American Diabetes Association: Diabetes basics, accessed Food, accessed 28 September.

Al-Rubeaan, K, Youssef, AM, Subhani, SN, Ahmad, NA, Al-Sharqawi, AH, et al, 2014: Diabetic nephropathy and its risk factors in a society with a type 2 diabetes epidemic: A Saudi national diabetes registry-based study. PLoS One. Feb 21;9(2):e88956. doi: 10.1371/journal. pone.0088956.eCollection.

Bedoya, S, Lam, B, Lau, K, Larkin, J, 2013: Th17 Cells in immunity and autoimmunity. Clin. Develop. Immunol.13:161-177

Benoist, C, Mathis, D, 2012: Treg Cells, Life History, and Diversity. Cold Spring Harb Perspect. Biol. 4, 9:a007021. doi: 10.1101/ cshperspect.a007021

Bogdan, M, McDonnell, M, Shin, H, Rehman, Q, Hasturk, H, et al, 2011: elevated proinflammatory cytokine production by a skewed $\mathrm{T}$ cell compartment requires monocytes and promotes inflammation in type 2 diabetes. J. Immuol. 186, 2:1162-72.

Bernadette, B, Kazuo, E, Zhezhen, J, 2007: Usefulness of fasting blood glucose to predict vascular outcome in diabetes mellitus. Amer. J. Cardiol. 100, 9:1404-9

Dodhia, S, Vidja, K, Bhabhor, M, Kathrotia, R, Vala, N, et al, 2011: 6 factors affecting progress-ion of nephropathy in type 2 diabetes mellitus. Indian J. Nephrol. 72:93-8

Duran-Salgado, MB, Rubio-Guerra, AF, 2014: Diabetic nephropathy and inflammation. World J. Diabetes 5, 3:393-8.

Endlich, N, Endlich K, 2006: Stretch, tension and adhesion-adaptive mechanisms of theaktin cytoskeleton in podocytes. Eur. J. Cell Biol. 85:229-34

El-Tawdy, AHF, Ibrahim, EA, Abdallah, ES, Al Sakhawy EMA, Morsy, TA, 2016: Screening for the diabetes mellitus: General information for patients to avoid foot amputation. EMMJ, 71, 1:61-74.

El-Wakf, A, Abbas, T, El-Baz, R, Mohammed, W, 2011: Role of hypertension and metabolic abnor-malities in the development of diabetic nephropathy among Egyptian Patients with Type 2 Diabetes. Nat. Sci. 9, 7:220-8
González-García, C, Martín-Saavedra, F, Ballester, A, Ballester S, 2009: The Th17 lineage: Answers to some immunological questions. Immunología 28: 32-45

Henry, R, Cannon, D, Winkelman, J, 1974: Clinical chemistry principles and techniques. In: Harpar, T, Raw, V (eds.), $2^{\text {nd }}$ edition: Textbook of Clinical Chemistry, USA.

Hundorfean, G, Neurath, M, Mudter, J, 2012: Functional relevance of $\mathrm{T}$ helper 17 cells and the IL-17 cytokine family in inflammatory bowel disease. Inflamm. Bowel Dis. 18:180-6

Johnson, A, Rohlfs, E, Silverman, L, 2001: Chemical Principles and Techniques. In W.B. Sanders Co. (eds.): Fifth edition; Tietz Textbook of Clinical Chemistry. USA.

Josefowicz, S, Lu, L, Rudensky, A, 2012: Regulatory T Cells: Mechanisms of differentiation and function. Ann. Rev. Immunol. 30: 531-64

K/DOQI, 2012: Kidney Disease Outcome Quality Initiative clinical practice guidelines and clinical practice recommendations for diabetes and chronic kidney disease: 2012 Update. Am. J. Kidn. Dis. 60, 5:850-86.

Lastovicka, J, 2013: The phenotypic markers of CD4 +CD25 + T regulatory lymphocytes. Inter. J. 198. 6:889-901

Lim, A, Tesch, G, 2012: Inflammation in Diabetic Nephropathy. Media. Inflamma. 20:12232.

Louten, J, Boniface, K, Malefyt, R, 2009: Development and function of TH17 in health and disease. J. Allergy Clin. Immunol. 123, 5:100411

Mellor, A, Munn, D, 2011: Physiologic control of the functional status of Foxp3 regulatory $\mathrm{T}$ cells. J. Immunol. 186:4535-40.

Philip, B, Glenn, D, Braunstien, G, 2006: Diabetes mellitus. In: Remon L (eds ): Fifth edition: Cecil Essentials of Internal Medicine, USA Immunol. 583,186:4535-40

Sakaguchi, S, Wing, K, Onishi, Y, PrietoMartin, P, Yamaguchi, T, 2009: Regulatory T cells: how do they suppress immune response?. Int. Immunol. 21:1105-11

Singh, B, Ari Schwartz, J, Sandrock, C, Bellemore, S, Nikoopour, E, 2012: Modulation of auto-immune diseases by interleukin -17 producing regulatory $\mathrm{T}$ helper 17 cells. Indian J. Med. Res. 138: 591-4

Stephen, T, Gian, CV, 2006: Diabetic nephrop 
athy, complications of diabetes. Medicine 34, 3: 83-6

Schmetterer, K, Neunkirchner, A, Pick, W, 2012: Naturally occurring regulatory $T$ cells: Markers, mechanisms, and manipulate. Faseb J. 26:324-30

Viswanathan, V, Snehalatha, C, Kumutha, R, Jayaraman, M, Ramachandran, A, 2004: Serum albumin levels in different stages of type 2 diabetic nephropathy patients. Indian J. Nephrol. 14:89-92

Varghesea, A, Deepa, R, Rema, M, Mohan, V, 2001: Prevalence of microalbuminuria in type 2 diabetes mellitus at a diabetes centre in southern India. Postgrad. Med. J. 77:399-402
Wu, C, Sytwu, H, Lu, K, Lin, Y, 2011: Role of T Cells in Type 2 Diabetic Nephropathy. Exp. Diab- etes Res.11:92-103

Yousef-idaredor, H, Zare-Bidaki, M, Hakimi, H, Assar, S, Bagheri, V, et al, 2014: IL-17A plays an important role in induction of type 2 diabetes and its complications. Asian Pac. J. Trop. Dis. 4, 5: 412-5

Zhang, C, Xiao, C, Wang, P, Xu, W, Zhang, A, et al, 2014: The alteration of Th1/Th2/ Th17 / Treg paradigm in patients with type 2 diabetes mellitus: Relationship with diabetic nephropathy. J. Human Immunol. 75:289-96 